\title{
A Facile Synthesis of Monodisperse Au Nanoparticles and Their Catalysis of CO Oxidation
}

\author{
Sheng Peng ${ }^{1}$, Youngmin Lee ${ }^{1}$, Chao Wang ${ }^{1}$, Hongfeng Yin $^{2}$, Sheng Dai $^{2}$, and Shouheng Sun ${ }^{1}(\varangle)$ \\ ${ }^{1}$ Department of Chemistry, Brown University, Providence, Rhode Island 02912, USA \\ ${ }^{2}$ Chemical Sciences Division, Oak Ridge National Laboratory, Tennessee 37831, USA \\ Received: 17 June 2008/ Revised: 19 July 2008/Accepted: 24 July 2008 \\ CTsinghua Press and Springer-Verlag 2008. This article is published with open access at Springerlink.com
}

\begin{abstract}
Monodisperse Au nanoparticles (NPs) have been synthesized at room temperature via a burst nucleation of Au upon injection of the reducing agent $t$-butylamine-borane complex into a 1, 2, 3, 4-tetrahydronaphthalene solution of $\mathrm{HAuCl}_{4} \cdot 3 \mathrm{H}_{2} \mathrm{O}$ in the presence of oleylamine. The as-synthesized Au NPs show size-dependent surface plasmonic properties between 520 and $530 \mathrm{~nm}$. They adopt an icosahedral shape and are polycrystalline with multiple-twinned structures. When deposited on a graphitized porous carbon support, the NPs are highly active for CO oxidation, showing $100 \% \mathrm{CO}$ conversion at $-45^{\circ} \mathrm{C}$.
\end{abstract}

\section{KEYWORDS}

Nanoparticle synthesis, Au nanoparticles, catalysis, CO oxidation

\section{Introduction}

The synthesis of catalytically active Au nanoparticles (NPs) has attracted great attention since Haruta's discovery that small $(<5 \mathrm{~nm})$ Au NPs catalyze the oxidation of carbon monoxide $(\mathrm{CO})$ at low temperatures [1-8]. Such NPs have also shown selective catalysis in oxidation or hydrogenation reactions [9-14]. Catalytically active Au NPs are often prepared by co-deposition of an Au salt with a metal oxide in order to establish an epitaxial relationship between $\mathrm{Au}$ and the oxide support. This requirement, however, has made the synthesis of Au nanocatalysts extremely challenging as the NPs prepared from such co-deposition methods are either not uniform and lack the required size control, or have very limited epitaxial links with the oxide support. Currently monodisperse $\mathrm{Au}$
NPs with size smaller than $10 \mathrm{~nm}$ are commonly synthesized by the reduction of $\mathrm{HAuCl}_{4}$ in an organic solvent, often with thiol molecules as stabilizing surfactants [15-17]. Although these monodisperse $\mathrm{Au}$ NPs have been studied extensively for their surface plasmonic properties and for their potential bioimaging applications [18-20], they are generally not catalytically active.

Here we report a facile organic phase synthesis of monodisperse Au NPs with sizes tunable from $1 \mathrm{~nm}$ to $10 \mathrm{~nm}$ using oleylamine (OAm) as NP stabilizer. The Au NPs are synthesized by a burst nucleation method using $t$-butylamine-borane complex, a reducing agent that was used recently [21] for the preparation of monodisperse $\mathrm{Au}$ and its alloy NPs via the reduction of $\mathrm{Au}\left(\mathrm{PPh}_{3}\right) \mathrm{Cl}$ in the presence of thiols at $55{ }^{\circ} \mathrm{C}$. The morphology, size-dependent surface plasmonic properties, and catalytic activity

Address correspondence to ssun@brown.edu 
in CO oxidation of the as-synthesized Au NPs have been investigated.

\section{Experimental}

The syntheses were carried out using commercially available reagents. Hydrogen tetrachloroaurate (III) hydrate $\left(\mathrm{HAuCl}_{4} \cdot 3 \mathrm{H}_{2} \mathrm{O}\right)$ was purchased from Strem Chemicals. Tert-butylamine-borane complex (TBAB, 97\%) and morpholine-borane complex (MB, 95\%) were purchased from Sigma Aldrich. Oleylamine (OAm) (C18 content: 80\%-90\%) and 1,2,3,4-tetrahydronaphthalene (tetralin, 95\%-98\%) were purchased from Acros Organics.

\subsection{Synthesis of 1-10 $\mathrm{nm}$ Au NPs}

In a typical synthesis of $6 \mathrm{~nm} \mathrm{Au}$ NPs, an orange precursor solution of tetralin $(10 \mathrm{~mL})$, OAm (10 $\mathrm{mL})$, and $\mathrm{HAuCl}_{4} \cdot 3 \mathrm{H}_{2} \mathrm{O}(0.1 \mathrm{~g})$ was prepared in air at room temperature (r.t., $\sim 20^{\circ} \mathrm{C}$ ) and magnetically stirred under $\mathrm{N}_{2}$ flow for $10 \mathrm{~min}$. A reducing solution containing $0.5 \mathrm{mmol}$ of $\mathrm{TBAB}$, tetralin $(1 \mathrm{~mL})$, and OAm (1 mL) was mixed by sonication and injected into the precursor solution. The reduction was instantaneously initiated and the solution changed to a deep purple color within $5 \mathrm{~s}$. The mixture was allowed to react at r.t. for $1 \mathrm{~h}$ before acetone $(60 \mathrm{~mL})$ was added to precipitate the Au NPs. The Au NPs were collected by centrifugation ( $8500 \mathrm{rpm}, 8 \mathrm{~min}$ ), washed with acetone and redispersed in hexane. The synthesis achieved nearly quantitative yield as the solution after NP precipitation was colorless.

In general, the Au NPs could be dispersed in various non-polar, or weakly polar, solvents, such as hexane, toluene, and chloroform. The Au NPs synthesized by $\mathrm{MB}$ reduction of Au salts were very similar in size and morphology to those synthesized using $\mathrm{TBAB}$ and are not discussed further in this paper.

By carefully controlling the reaction temperature, Au NPs with different sizes could be readily synthesized. For example, to prepare $2 \mathrm{~nm} \mathrm{Au} \mathrm{NPs,}$ the $\mathrm{Au}$ precursor mixture was heated to $40{ }^{\circ} \mathrm{C}$ using a heating mantle for $10 \mathrm{~min}$. A reducing solution was then injected into the light-yellow colored precursor solution, and the reaction mixture was kept at that temperature for $1 \mathrm{~h}$ before cooling to r.t. To synthesize
$10 \mathrm{~nm} \mathrm{Au} \mathrm{NPs,} \mathrm{the} \mathrm{reaction} \mathrm{mixture} \mathrm{was} \mathrm{cooled} \mathrm{down}$ to $2{ }^{\circ} \mathrm{C}$ using an ice-water bath. It took about $5 \mathrm{~min}$ for the reaction mixture to become deep purple after injection of the reducing agent. The reaction mixture was subsequently kept at $2{ }^{\circ} \mathrm{C}$ for $1 \mathrm{~h}$ before warming to r.t. Reaction temperatures required for the syntheses of $\mathrm{Au}$ NPs with different sizes are listed in Table 1.

Table 1 Average size of Au NPs synthesized at different temperatures

\begin{tabular}{c|c}
\hline Reaction temperature $\left({ }^{\circ} \mathrm{C}\right)$ & Avg. Au NP size $(\mathrm{nm})$ \\
\hline 2 & 9.5 \\
10 & 8.1 \\
15 & 7.3 \\
20 & 6.4 \\
25 & 5.3 \\
35 & 3.3 \\
40 & 2.4 \\
\hline
\end{tabular}

\subsection{NP characterization}

Samples for transmission electron microscopy (TEM) analysis were prepared by drying a dispersion of the particles on amorphous carbon-coated copper grids. Particles were imaged using a Philips EM 420 $(120 \mathrm{kV})$. High-resolution TEM (HRTEM) images were recorded using a Jeol JEM-2010 (200 kV). Au NPs deposited on a graphitized porous carbon support were imaged by a Joel JSM-6060 scanning electron microscopy (SEM). X-ray diffraction (XRD) patterns of the particle assemblies were collected on a Bruker AXS D8-Advance diffractometer with $\mathrm{Cu}$ $\mathrm{K} \alpha$ radiation $(\lambda=1.5418 \AA$ ). $\mathrm{UV} / \mathrm{vis}$ spectra were recorded on a Perkin Elmer Lambda 35 spectrometer.

\subsection{NP catalyzed CO oxidation}

To perform the $\mathrm{CO}$ oxidation reaction tests, $6 \mathrm{~nm} \mathrm{Au}$ NPs were deposited on a graphitized porous carbon support (Carbopack 120/400 mesh, Supelco). The catalyst was packed into a U-shaped silica tube (4 mm i.d.) in an Altamira AMI 200 microreactor and calcined at $300{ }^{\circ} \mathrm{C}$ in $8 \% \mathrm{O}_{2} / \mathrm{He}$ mixture for $1 \mathrm{~h}$ in order to remove the OAm surfactant. The catalyst was subsequently cooled down and the gas stream was switched to $1 \% \mathrm{CO}$ (balance air, $<4$ ppm $\mathrm{H}_{2} \mathrm{O}$ ) at a flow rate of $37 \mathrm{~cm}^{3} / \min$ (space velocity $41900 \mathrm{~cm}^{3} /$ $\left.\left(h \cdot g_{\text {cat }}\right)\right)$. A portion of the product stream was extracted periodically with an automatic sampling valve and 
analyzed by means of a dual-column GC with a thermal conductivity detector.

\section{Results and discussion}

Figure 1 shows transmission electron microscopy (TEM) images of the $6 \mathrm{~nm}$ and $9 \mathrm{~nm} \mathrm{Au} \mathrm{NPs}$ synthesized in this work. Figure 1(a) shows the $6 \mathrm{~nm}$ $\mathrm{Au}$ NPs which have a standard deviation in their diameter of less than $7 \%$. Figure 1(b) shows the selfassembled $6 \mathrm{~nm} \mathrm{Au} \mathrm{NP} \mathrm{superlattice} \mathrm{array.} \mathrm{It} \mathrm{was}$ obtained by direct deposition of the $6 \mathrm{~nm}$ Au NP hexane dispersion on an amorphous carbon coated copper grid followed by slow evaporation $(5 \mathrm{~min}$ ) of hexane. The assembly shows typical hexagonal close packing of the Au NPs. HRTEM studies of the NPs reveal that each NP tends to adopt an icosahedral morphology with multiple-twinned structures. An icosahedron has $20\{111\}$ facets, and has three types of rotational axes: twofold, threefold, and fivefold. Figure 1(c) shows HRTEM images of three $9 \mathrm{~nm} \mathrm{Au}$ NPs imaged along three different rotational axes. The interplanar distance measured from the adjacent lattice fringes is $0.236 \mathrm{~nm}$, corresponding to the (111) planes of face centered cubic (fcc) Au. This multi-

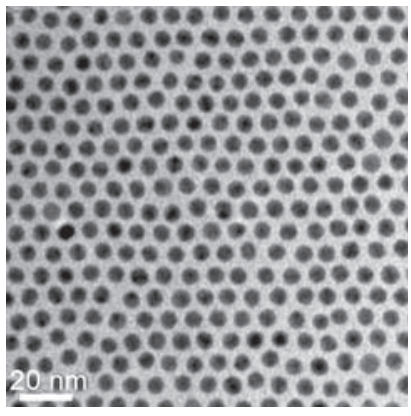

(a)
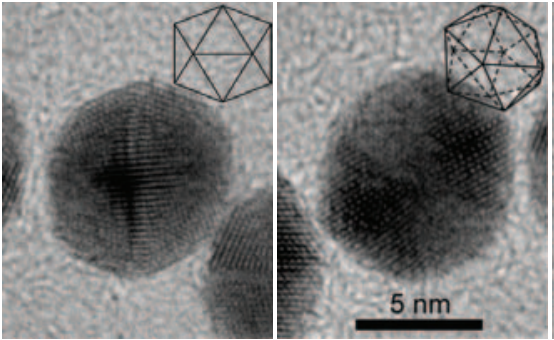

(c)

Figure 1 (a) TEM image of the $6 \mathrm{~nm}$ Au NPs; (b) TEM image of the self-assembled $6 \mathrm{~nm}$ Au NP superlattice; (c) HRTEM images of the 9 $\mathrm{nm}$ Au icosahedral NPs with different orientations. The insets show corresponding schematic illustrations of the icosahedron. A twinned plane is marked in red twinned icosahedral structure is frequently observed in fcc metallic NPs having small sizes [22-24]. Maximization of the $\{111\}$ planes in an icosahedron by forming twinned planes minimizes the surface energy and compensates the extra strain energy generated by the twinned defects [25].

The size of the Au NPs is dependent on the reaction temperature at which the reducing agent is injected. For example, $2 \mathrm{~nm}$ Au NPs were prepared by injecting the reducing solution at $40{ }^{\circ} \mathrm{C}$, while reactions carried out at $15^{\circ} \mathrm{C}$ and at $0{ }^{\circ} \mathrm{C}$ gave uniform $7 \mathrm{~nm}$ and $10 \mathrm{~nm}$ Au NPs, respectively. By controlling the reaction temperature, we could finely tune the sizes of Au NPs in steps of ca. $1 \mathrm{~nm}$ (Table 1 and Fig. 2). However, cooling the reaction below $10{ }^{\circ} \mathrm{C}$ led to the decrease in solubility of the $\mathrm{HAuCl}_{4}$ precursor in tetralin/OAm mixture and consequently a slightly wider size distribution in the Au NPs (Fig. 2(f)).

The formation of Au NPs under the synthesis conditions employed can be explained by the classic La Mer theory [26, 27]. Upon injection of the reducing agent at room temperature, a burst nucleation event occurs, which is indicated by the observation of an immediate color change. At relatively high temperatures (room temperature for example), this burst nucleation consumes most of the precursors, leading to fast nucleation and growth processes, and smaller $\mathrm{Au} \mathrm{NPs.} \mathrm{In} \mathrm{the} \mathrm{synthesis,} \mathrm{the} \mathrm{size} \mathrm{of}$ the $\mathrm{Au} \mathrm{NPs} \mathrm{is} \mathrm{strongly} \mathrm{dependent} \mathrm{on} \mathrm{the} \mathrm{reaction}$ temperature, and independent of the concentration of the precursor or on the reaction time-aliquots removed at different reaction times after the injection showed little size change. As shown in Fig. 3(a), a linear correlation can be seen between reaction temperature and nanoparticle size.

XRD of the Au NP assemblies show typical fcc Au diffraction patterns (Fig. 3(b)). However, the strongest (111) peak shifts slightly to higher angle as the particle size decreases. This peak shift may originate from the change in lattice constant resulting from the strain in the twinned structures. The grain size estimated from the XRD patterns using Scherrer's equation is smaller than that measured from the TEM images, indicating that the icosahedral NPs are polycrystalline. UV/vis spectra of the Au NPs dispersed in hexane exhibit the characteristic $\mathrm{Au}$ 


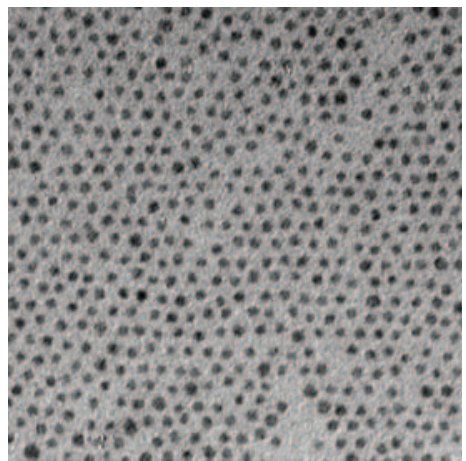

(a)

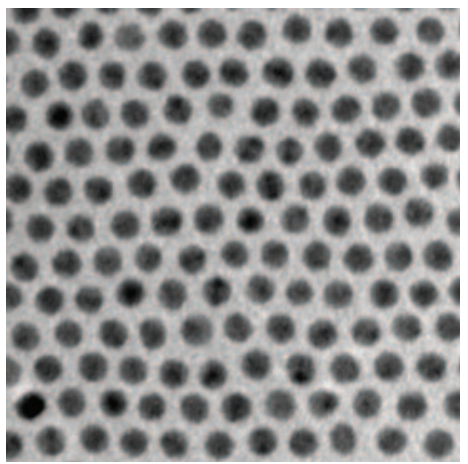

(d)

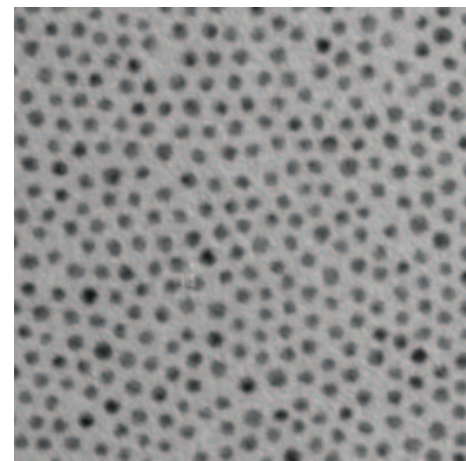

(b)

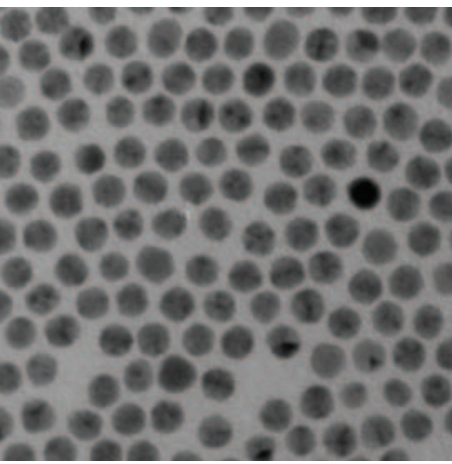

(e)

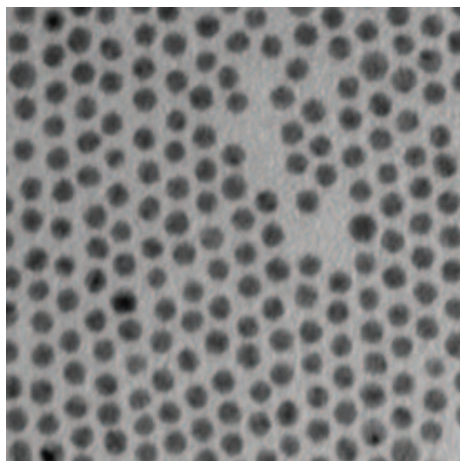

(c)

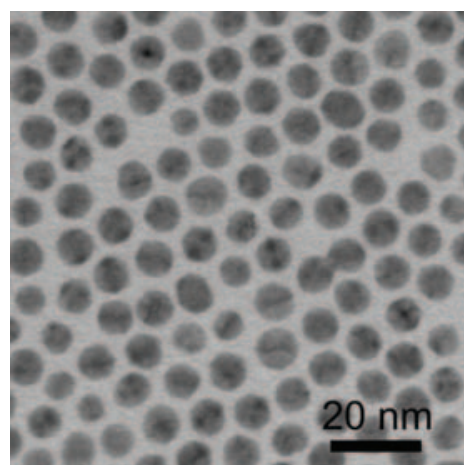

(f)

Figure 2 TEM images of the Au NPs synthesized at different temperatures: (a) $40^{\circ} \mathrm{C}$, (b) $35^{\circ} \mathrm{C}$, (c) $25^{\circ} \mathrm{C}$, (d) $15^{\circ} \mathrm{C}$, (e) $10^{\circ} \mathrm{C}$, and (f) $2^{\circ} \mathrm{C}$

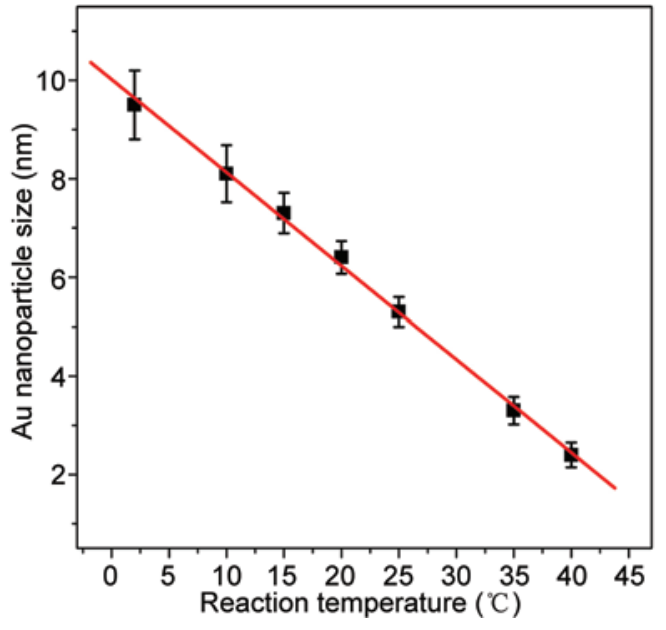

(a)

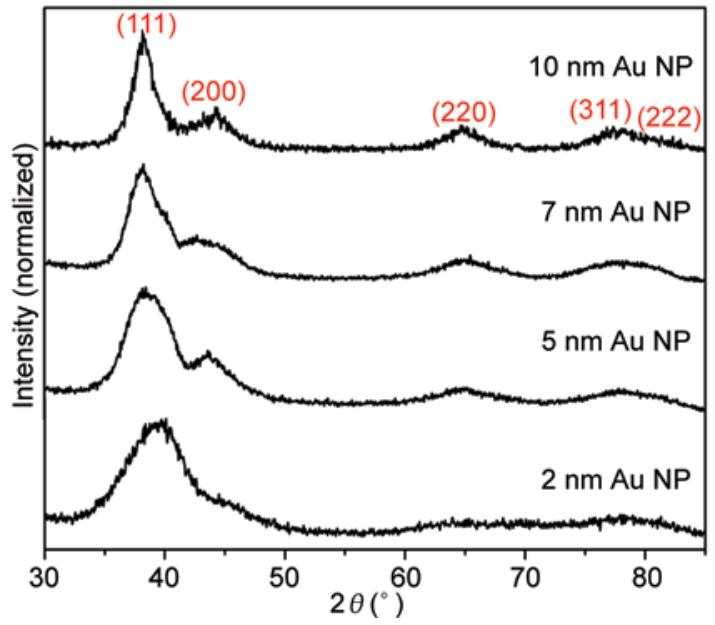

(b)

Figure 3 (a) Average size of Au NPs synthesized at different temperatures. The size was measured from the respective TEM images; (b) XRD patterns of the Au NPs of different sizes

surface plasmon absorption between 520 and $530 \mathrm{~nm}$ (Fig. 4). As the NP size increases, the peak intensity increases with its position being slightly red-shifted: this is commonly observed for Au NPs as a result of the increased electron density in larger NPs [15].

We chose $6 \mathrm{~nm}$ Au NPs as an example catalyst for $\mathrm{CO}$ oxidation as they were readily synthesized at r.t.
Our preliminary catalytic studies show that the $6 \mathrm{~nm}$ $\mathrm{Au}$ NPs deposited on a graphitized porous carbon support followed by calcination at $300{ }^{\circ} \mathrm{C}$ under He $+\mathrm{O}_{2}(8 \%)$ can catalyze the oxidation of $\mathrm{CO}$ at low temperature. Figure 5(a) shows the high-resolution scanning electron microscopy (HRSEM) image of the $\mathrm{Au}$ NPs deposited on the carbon support and 


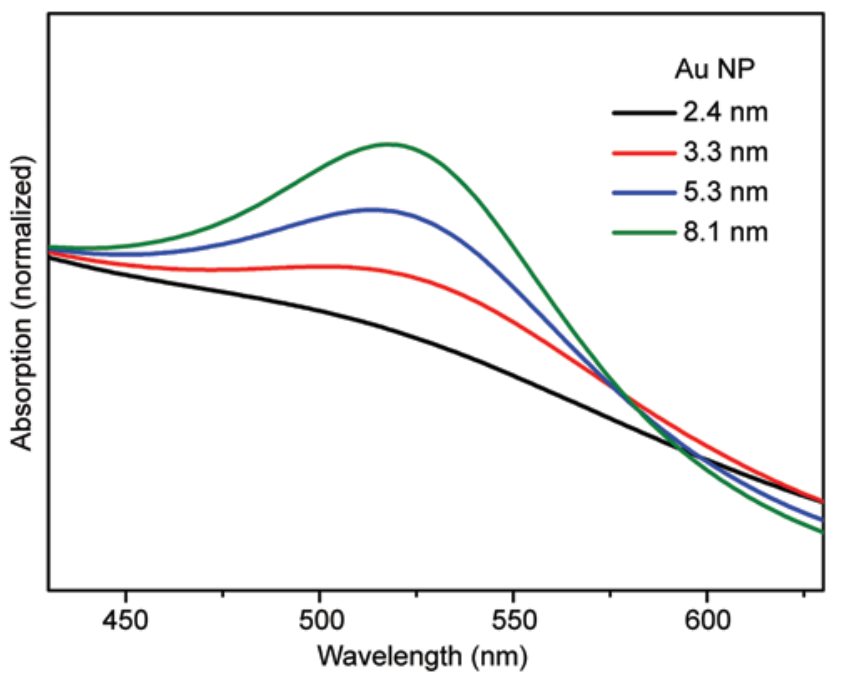

Figure 4 UV/vis spectra of Au NPs of different sizes

Fig. 5(b) shows the light-off curve for the Au/C catalyst. A $100 \%$ conversion was achieved even at $-45^{\circ} \mathrm{C}$. This is in marked contrast to what has been previously observed for Au NPs synthesized in a conventional solution phase and loaded directly

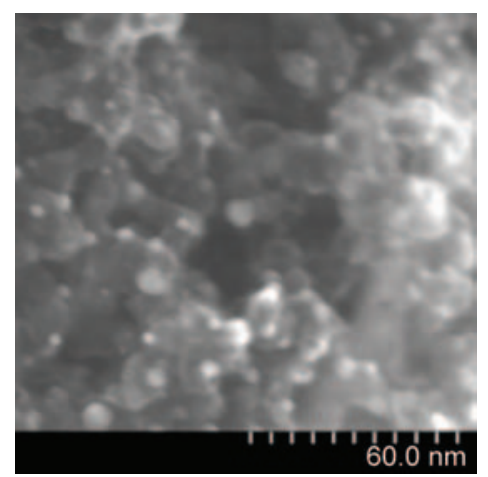

(a)

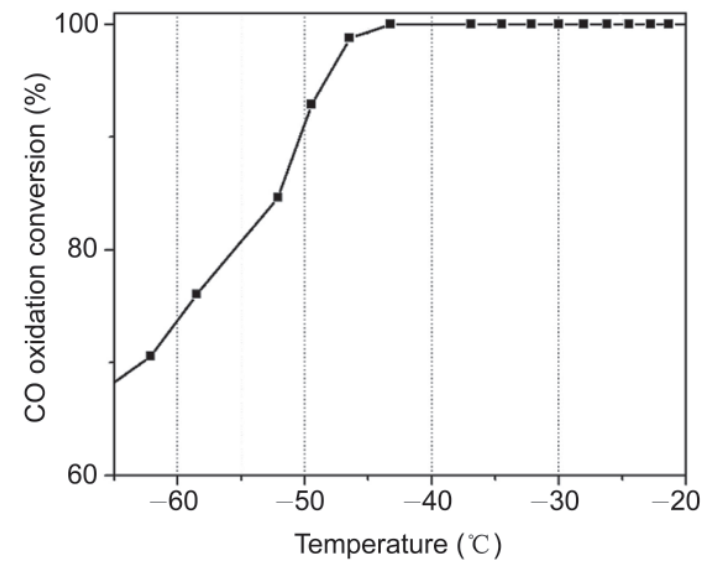

(b)

Figure 5 (a) HRSEM image of the $6 \mathrm{~nm}$ Au NPs on the graphitized porous carbon support and (b) $\mathrm{CO}$ oxidation conversion light-off curve of the Au nanocatalyst shown in (a) onto carbon supports; such materials are inactive for $\mathrm{CO}$ oxidation because of the lack of metal-oxide interfaces [28].

The enhanced catalysis of the Au NPs prepared in this work may be due to the presence of the twinned boundaries in the polycrystalline structure. Detailed structural and catalytic studies on these monodisperse Au NPs are underway.

\section{Conclusions}

We have developed a facile organic phase synthesis of monodisperse non-thiol capped Au NPs via a burst nucleation of $\mathrm{Au}$ upon injection of a $t$-butylamineborane complex. The Au NPs have icosahedral shape and are polycrystalline with twinned structures. They are highly active for CO oxidation, achieving 100\% $\mathrm{CO}$ oxidation conversion at $-45{ }^{\circ} \mathrm{C}$. We are currently studying the structural and catalytic properties of these Au NPs on various supports in order to develop a new class of Au catalyst for the controlled oxidation of organic molecules.

\section{Acknowledgements}

The work was supported by NSF/DMR 0606264 and a GAANN fellowship (Y. Lee). The authors thank Anthony W. McCormick for his help in acquiring HRTEM images of the Au NPs.

\section{References}

[1] Haruta, M.; Yamada, N.; Kobayashi, T.; lijima, S. Gold catalysts prepared by coprecipitation for low-temperature oxidation of hydrogen and of carbon monoxide. J. Catal. 1989, 115, 301-309.

[2] Haruta, M.; Tsubota, S.; Kobayashi, T.; Kageyama, H.; Genet, M. J.; Delmon, B. Low-temperature oxidation of $\mathrm{CO}$ over gold supported on $\mathrm{TiO}_{2}, \alpha-\mathrm{Fe}_{2} \mathrm{O}_{3}$, and $\mathrm{CO}_{3} \mathrm{O}_{4}$. J. Catal. 1993, 144, 175-192.

[3] Grunwaldt, J. D.; Kiener, C.; Wögerbauer, C.; Baiker, A. Preparation of supported gold catalysts for lowtemperature CO oxidation via "size-controlled" gold colloids. J. Catal. 1999, 181, 223-232.

[4] Haruta, M. Gold as a novel catalyst in the $21^{\text {st }}$ century: Preparation, working mechanism and applications. Gold

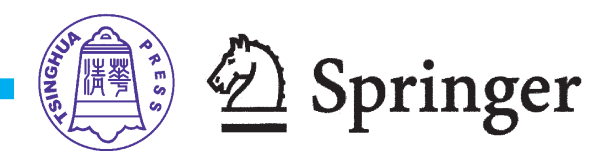


Bull. 2004, 37, 27-36.

[5] Carrettin, S.; Concepcion, P.; Corma, A.; Nieto, J. M. L.; Puntes, V. F. Nanocrystalline $\mathrm{CeO}_{2}$ increases the activity of $\mathrm{Au}$ for $\mathrm{CO}$ oxidation by two orders of magnitude. Angew. Chem. Int. Ed. 2004, 43, 2538-2540.

[6] Kim, W. B.; Voitl, T.; Rodriguez-Rivera, G. J.; Dumesic, J. A. Powering fuel cells with $\mathrm{CO}$ via aqueous polyoxometalates and gold catalysts. Science 2004, 305, 1280-1283.

[7] Zhu, H. G.; Liang, C. D.; Yan, W. F.; Overbury, S. H.; Dai, S. Preparation of highly active silica-supported Au catalysts for CO oxidation by a solution-based technique. J. Phys. Chem. B 2006, 110, 10842-10848.

[8] Overbury, S. H.; Schwartz, V.; Mullim, D. R.; Yan, W. F.; Dai, S. Evaluation of the Au size effect: CO oxidation catalyzed by $\mathrm{Au} / \mathrm{TiO}_{2}$. J. Catal. 2006, 241, 56-65.

[9] Carrettin, S.; McMorn, P.; Johnston, P.; Griffin, K.; Kiely, C. J.; Attard, G. A.; Hutchings, G. J. Oxidation of glycerol using supported gold catalysts. Top. Catal. 2004, 27, 131136.

[10] Zanella, R.; Louis, C.; Giorgio, S.; Touroude, R. J. Crotonaldehyde hydrogenation by gold supported on $\mathrm{TiO}_{2}$ : Structure sensitivity and mechanism. J. Catal. 2004, 223, 328-339.

[11] Milone, C.; Ingoglia, R.; Galvagno, S. Gold supported on iron oxy-hydroxides: A versatile tool for the synthesis of fine chemicals. Gold Bull. 2006, 39, 54-65.

[12] Abad, A.; Corma, A.; Garcia, H. Supported gold nanoparticles for aerobic, solventless oxidation of allylic alcohols. Pure Appl. Chem. 2007, 79, 1847-1854.

[13] Corma, A.; Concepcion, P.; Serna, P. A different reaction pathway for the reduction of aromatic nitro compounds on gold catalysts. Angew. Chem., Int. Ed. 2007, 46, 7266-7269.

[14] Corma, A.; Serna, P.; Garcia, H. Gold catalysts open a new general chemoselective route to synthesize oximes by hydrogenation of alpha, beta-unsaturated nitrocompounds with $\mathrm{H}_{2}$. J. Am. Chem. Soc. 2007, 129, 6358-6359.

[15] Daniel, M.C.; Astruc, D. Gold nanoparticles: Assembly, supramolecular chemistry, quantum-size-related properties, and applications toward biology, catalysis, and nanotechnology. Chem. Rev. 2004, 104, 293-346.

[16] Fan, H. Y.; Yang, K.; Boye, D. M.; Sigmon, T.; Malloy, K. J.; Xu, H. F.; Lopez, G. P.; Brinker, C. J. Self-assembly of ordered, robust, three-dimensional gold nanocrystal/silica arrays. Science 2004, 304, 567-571.

[17] Bigioni, T. P.; Lin, X. M.; Nguyen, T. T.; Corwin, E. I.; Witten, T. A.; Jaeger, H. M. Kinetically driven self assembly of highly ordered nanoparticle monolayers. Nat. Mater. 2006, 5, 265-270.

[18] Tkachenko, A. G.; Xie, H.; Liu, Y. L.; Coleman, D.; Ryan, J.; Glomm, W. R.; Shipton, M. K.; Franzen, S.; Feldheim, D. L. Cellular trajectories of peptide-modified gold particle complexes: Comparison of nuclear localization signals and peptide transduction domains. Bioconjugate Chem. 2004, 15, 482-490.

[19] Haes, A. J.; Haynes, C. L.; McFarland, A. D.; Schatz, G. C.; van Duyne, R. R.; Zou, S. L. Plasmonic materials for surface-enhanced sensing and spectroscopy. MRS Bull. 2005, 30, 368-375.

[20] Rosi, N. L.; Mirkin, C. A. Nanostructures in biodiagnostics. Chem. Rev. 2005, 105, 1547-1562.

[21] Zheng, N.; Fan, J.; Stucky, J. D. One-step one-phase synthesis of monodisperse noble-metallic nanoparticles and their colloidal crystals. J. Am. Chem. Soc. 2006, 128, 6550-6551.

[22] Baletto, F.; Ferrando, R. Microscopic mechanisms of the growth of metastable silver icosahedra. Phys. Rev. B 2001, 63, 155408.

[23] Baletto, F.; Ferrando, R.; Fortunelli, A.; Montalenti, F.; Mottet, C. Crossover among structural motifs in transition and noble-metal clusters. J. Chem. Phys. 2002, 116, 3856-3863.

[24] Xiong, Y.; McLellan, J. M.; Yin, Y.; Xia, Y. Synthesis of palladium icosahedra with twinned structure by blocking oxidative etching with citric acid or citrate ions. Angew. Chem., Int. Ed. 2007, 46, 790-794.

[25] Wang, Z. L. Transmission electron microscopy of shapecontrolled nanocrystals and their assemblies. J. Phys. Chem. B 2000, 104, 1153-1175.

[26] La Mer, V. K.; Dinegar, R. H. Theory, production and mechanism of formation of monodispersed hydrosols. J. Am. Chem. Soc. 1950, 72, 4847-4854.

[27] Murray, C. B.; Kagan, C. R.; Bawendi, M. G. Synthesis and characterization of monodisperse nanocrystals and close-packed nanocrystal assemblies. Annu. Rev. Mater. Sci. 2000, 30, 545-610.

[28] Ma, Z.; Liang, C. D.; Overbury, S. H.; Dai, S. Gold nanoparticles on electroless-deposition-derived $\mathrm{MnO}_{x} / \mathrm{C}$ : Synthesis, characterization, and catalytic CO oxidation. J. Catal. 2007, 252, 119-126. 